\title{
Cloning and Molecular Characterization of the Ontogeny of a Rat lleal Sodium-dependent Bile Acid Transporter
}

\author{
Benjamin L. Shneider, ${ }^{*}$ Paul A. Dawson, ${ }^{\ddagger}$ Donna-Marie Christie, ${ }^{\star}$ Winita Hardikar, ${ }^{*}$ Melissa H. Wong, ${ }^{\ddagger}$ \\ and Frederick J. Suchy* \\ * Department of Pediatrics, Division of Pediatric Gastroenterology/Hepatology, Yale University School of Medicine, New Haven, \\ Connecticut 06520; and ${ }^{\ddagger}$ the Department of Internal Medicine-Gastroenterology, Bowman Gray School of Medicine, \\ Wake Forest University, Winston-Salem, North Carolina 27157
}

\begin{abstract}
Sodium-dependent bile acid transport in the rat ileum is abruptly expressed at weaning. Degenerate oligonucleotides, based on amino acid sequence identities between the rat liver and hamster ileal transporters, were used to amplify a rat ileal probe. A 1.2-kb cDNA clone, which contains the full coding region ( 348 amino acids, $38 \mathrm{kD}$ ), was isolated by hybridization screening. In vitro translation yielded a 38kD protein which glycosylated to $48 \mathrm{kD}$. Sodium-dependent uptake of taurocholate was observed in oocytes injected with cRNA. Northern blot analysis revealed a 5.0-kb mRNA in ileum, kidney, and cecum. $A$ 48-kD protein was detected in ileal brush border membranes and localized to the apical border of villus ileal enterocytes. mRNA and protein expression, which were negligible before weaning, increased dramatically at weaning. Nuclear transcription rates for the transporter increased 15-fold between postnatal days 7 and 28. The apparent molecular weight of the transporter also increased between days 19 and 28 . In summary, the developmental regulation of the rat ileal sodium-dependent bile acid cotransporter is characterized by transcriptionally regulated increases in mRNA and protein levels at the time of weaning with changes in apparent molecular weight of the protein after weaning. (J. Clin. Invest. 1995. 95:745-754.) Key words: ileum - development $\cdot$ bile salt - transport • transcription
\end{abstract}

\section{Introduction}

Sodium-dependent uptake of bile salts at the apical border of ileal enterocytes is ontogenically regulated (1-5). Using everted intestinal rings, mucosal uptake of taurocholate has been demonstrated in 2-wk-old dogs. and rats, with an absence of concentrative capacity at younger ages $(1,2)$. Sodium-dependent uptake of taurocholate has been observed in humans using intestinal rings prepared from the ileum of an 8-mo-old child but was not present in neonatal or fetal tissue (3). Kinetic

\footnotetext{
Address correspondence to Benjamin Shneider, M.D., Yale University, Department of Pediatrics, 333 Cedar Street, New Haven, CT 06520. Phone: 203-785-4649; FAX: 203-785-7194.

Received for publication 7 March 1994 and in revised form 4 October 1994.
}

J. Clin. Invest.

(C) The American Society for Clinical Investigation, Inc. 0021-9738/95/02/0745/10 \$2.00

Volume 95, February 1995, 745-754 analysis using brush border membrane vesicles (BBMV) ${ }^{1}$ from rat ileum showed that this phenomenon was related to the expression of carrier-mediated sodium-dependent bile acid transport activity $(4,5)$. The onset of this transport function is relatively abrupt. At postnatal day 16 there is no evidence of sodium-dependent transport, while it is clearly present at $17 \mathrm{~d}$. Concentrative uptake, indicated by "overshoot-transport," is not seen until day 18 , and the $V_{\max }$ for this system reaches $75 \%$ of adult levels by $21 \mathrm{~d}(5)$.

The mechanisms controlling the ontogenic regulation of ileal bile acid transport are not well understood. Endogenous surges in corticosteroid and thyroid hormones may be involved as evidenced by their capacity to induce precocious expression of transport activity in suckling animals $(6,7)$. Bile flow increases during the first weeks of postnatal life in the rat as a result of expansion of the bile salt pool and maturation of the hepatic basolateral and canalicular transporters (8). The subsequent increase in presentation of bile salts to the terminal ileum may also influence development, since gavage administration of bile salts induced precocious expression of transport activity (9). It is unknown what role "hard-wiring" plays in this process (10). There is conflicting evidence as to the role of intestinal brush border membrane fluidity changes during development and their effect on bile salt transport capacities $(11,12)$.

Further understanding of the developmental regulation of this system has been hindered by the absence of molecular probes for this carrier. The recent expression cloning of the sodium-dependent bile acid cotransporters on the rat liver basolateral membrane (BSBT) and the hamster ileum apical border (ASBT) has permitted us to clone the rat ASBT and examine its ontogeny at a molecular level $(13,14)$. Sequence analyses of the rat BSBT and hamster ASBT revealed that there were three stretches of at least six amino acids each which were conserved across tissue and species lines. Two of these regions were used to design degenerate oligonucleotide primers to amplify a probe which led to the cloning and molecular characterization of the rat ileal transporter. The developmental regulation of this system was then examined at the level of transcription, mRNA, and protein expression.

\section{Methods}

Materials. An oligo dT primed rat ileal XZAP II cDNA library was the generous gift of Raymond N. DuBois (Vanderbilt University Medical Center, Nashville, TN). AmpliTaq DNA polymerase was purchased

1. Abbreviations used in this paper: ASBT, apical sodium-dependent bile acid transporter (gene name slc15a2); BBMV, brush border membrane vesicles; BSBT, basolateral sodium-dependent bile acid transporter (gene name slc15al, formerly ntcp ). 
Rat lleal Bile Acid Transporter

Clone BS37C1

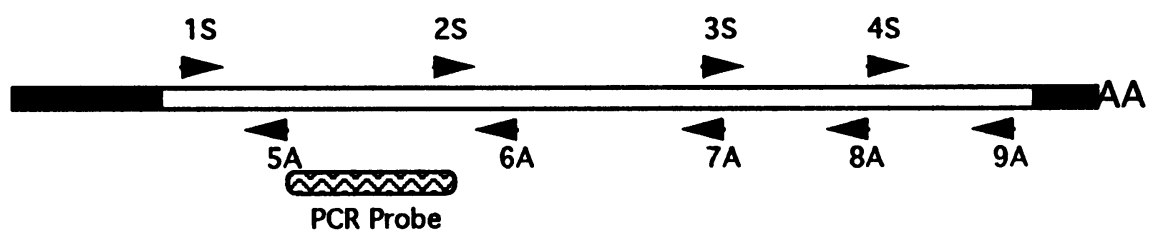

open reading frame coding region $1044 \mathrm{bp}$

$100 \mathrm{bp}$

1S=CAGTGATGAGCACCGTGCTC
2S=GACCACTTGCTCCACACTG
3S=CTGGCTACAGCCTTGGTTTC
4S=GTCACATACAAGAAATGTCATGG
Figure 1. Schematic of ileal cDNA clone BS37C1. The ileal cDNA clone BS37C1 consists of 115 and $80 \mathrm{bp}$ of $5^{\prime}$ and $3^{\prime}$ untranslated sequences. The locations and sequences of the sequencing oligonucleotides are shown. The degenerate oligonucleotide PCR product was designed to hybridize to the 5 '-end of the gene. from Perkin Elmer Cetus Corp. (Norwalk, CT). Degenerate oligonucleotide primers were synthesized by $\beta$-cyanoethyl phosphoramidite chemistry on a solid support (William Keck Biotechnology Resource Laboratory at Yale University, New Haven, CT). Rabbit reticulocyte lysates and dog pancreatic microsomes were purchased from Promega Corp. (Madison, WI). $\left[{ }^{3} \mathrm{H}\right]$ Taurocholate $(2.0 \mathrm{Ci} / \mathrm{mmol}),\left[{ }^{32} \mathrm{P}\right] \mathrm{dCTP}, \mathrm{CTP}$ (both $30,00 \mathrm{Ci} / \mathrm{mmol}$ ), and $\mathrm{L}-\left[{ }^{35} \mathrm{~S}\right]$ methionine $(1175 \mathrm{Ci} / \mathrm{mmol})$ were purchased from DuPont-New England Nuclear (Boston, MA). Recombinant $N$-glycanase was purchased from Genzyme Corp. (Cambridge, MA). Autofluor was purchased from National Diagnostics Inc. (Manville, NJ). Xenopus laevis toads (oocyte-positive females) were obtained from Xenopus I (Ann Arbor, MI). Sprague-Dawley rats were obtained from Charles River (Raleigh, NC). Adult rats weighed between 200 and $250 \mathrm{~g}$.

Animal care. Animals were housed, fed, and handled according to the NIH Guide for the Care and Use of Laboratory Animals and under a protocol approved by the Yale Animal Care and Use Committee. Sprague-Dawley rat pups were housed with their mother and were exposed to 12-h day/night cycles. They were weaned at $21 \mathrm{~d}$.

cDNA cloning and sequencing. Lambda phage DNA was prepared from liquid culture lysates of the amplified rat ileal cDNA library (15). A rat ileal-specific probe was amplified from this DNA using two oligonucleotide primers (sense primer with BamHI linker, CGGGATCCCAGTTTGG(C/A)ATCATGCC (C/T)CTC and antisense primer with EcoRI linker GGAATTC(A/G)AG(G/T)GGCATCAT(G/T)CC(A/ C) $A(A / G) G G C)$, which were degenerate for the nucleotide sequences of the conserved amino acid sequences of the rat BSBT protein (13) (amino acids [aa] 68-74 and 130-136) and the hamster ASBT (14) (aa 75-81 and 137-143). PCR amplification was carried out according to the manufacturer's (Perkin Elmer Cetus Corp.) guidelines with an annealing temperature of $55^{\circ} \mathrm{C}$. The 206-bp product was concentrated using a Centricon-100 apparatus (Amicon, Beverly, MA), digested with BamHI and EcoRI (New England Biolabs Inc., Beverly, MA), purified by agarose gel electrophoresis, and ligated into a BamHI/EcoRI-digested pBluescript II SK ${ }^{+}$(Stratagene, La Jolla, CA). Nucleic acid sequencing of the subcloned product was performed at the William Keck Biotechnology Resource Laboratory using AmpliTaq DNA polymerase and an ABI 373A automated sequencing system (Applied Biosystems Inc., Foster City, CA) (reference 16).

The 206-bp subcloned product above was labeled with $\left[{ }^{32} \mathrm{P}\right] \mathrm{dCTP}$ by random primed synthesis (GIBCO-BRL, Gaithersburg, MD) and used to screen the rat ileal cDNA library using standard filter hybridization techniques (17). On tertiary screen nine clones were isolated, one of which (BS37C1) was directly subcloned into pBluescript using the ExAssist/SOLR system according to the manufacturer (Stratagene).
Both strands of the 1,242-bp insert were sequenced using a series of oligonucleotide primers (Fig. 1). Sequence analysis was performed using software of the Genetics Computer Group (Madison, WI).

In vitro translation and oocyte expression. Capped cRNA was synthesized from KpnI-linearized plasmid using T3 polymerase (Promega Corp.). $2 \mu \mathrm{g}$ of cRNA were translated with a rabbit reticulocyte lysate and $L-\left[{ }^{35} \mathrm{~S}\right]$ methionine in the presence of $0.5 \%$ Triton X-100. Translation in the presence of canine pancreatic microsomes without detergent was used to examine the effect of glycosylation on the electrophoretic mobility of the product. Brome mosaic virus RNA was used as a positive control and its translation products served as molecular weight markers $(18,19)$. The specificity of the effect of the microsomes was assessed by digesting the product overnight with $N$-glycanase. Samples were solubilized in Laemmli buffer ( $1.37 \mathrm{M}$ glycerol, $0.7 \mathrm{M} \beta$-mercaptoethanol, $0.07 \mathrm{M}$ SDS, $0.06 \mathrm{M}$ Tris, $\mathrm{pH} 6.8$ ) at $37^{\circ} \mathrm{C}$, separated by $8 \%$ SDS-PAGE, and detected by autoradiography after enhancement with Autofluor.

$X$. laevis oocytes were prepared as described previously (20), injected with $9 \mathrm{ng}$ of cRNA, and cultured for $60 \mathrm{~h}$. 1-h uptake of $20 \mu \mathrm{M}$ $\left[{ }^{3} \mathrm{H}\right]$ taurocholate was measured in the presence of $100 \mathrm{mM}$ sodium or choline chloride (13). Inhibition by other bile salts was tested by adding $100 \mu \mathrm{M}$ glycocholate to the sodium incubation solution. Data are expressed as the mean \pm standard deviation and represent the results of at least three separate injections of cRNA. Means were compared using Students $t$ test.

Messenger RNA analysis. For Northern and Western blot analyses, the terminal ileum was defined as the terminal $20 \%$ of the length of the small bowel. For developmental studies, the terminal ileum was removed from $7,14,16,17,18,19,21$, and 28-d-old rat pups, flushed with ice cold normal saline, and then rapidly frozen in liquid nitrogen. Total RNA was extracted with guanidinium isothiocyanate and purified through a $\mathrm{CsCl}$ cushion (21). Poly (A) ${ }^{+}$RNA was purified using oligo dT linked to magnetic beads according to the manufacturer (Promega Corp.). Total or poly (A) ${ }^{+}$RNA was separated by electrophoresis through a $1.6 \mathrm{M}$ formaldehyde, $1.2 \%$ agarose gel, transferred by capillary action to a GeneScreen membrane (New England Nuclear Research, Boston, MA), and cross-linked with ultraviolet irradiation. The 1.2-kb insert of BS37C1 was released by digestion with XhoI and EcoRI and labeled with $\left[{ }^{32} \mathrm{P}\right] \mathrm{dCTP}$. Hybridization and high stringency washes were performed according to manufacturers instructions (New England Nuclear Research). Exposed $x$-ray films were developed and scanned (LKB Ultroscan XL, Bromma, Sweden). RNA preparation, blotting, and hybridization were done in triplicate. Gel loading was assessed by densitometry of the ethidium bromide staining of the $28 \mathrm{~S}$ band. To confirm that equal amounts of RNA were loaded in each lane, the blots were 


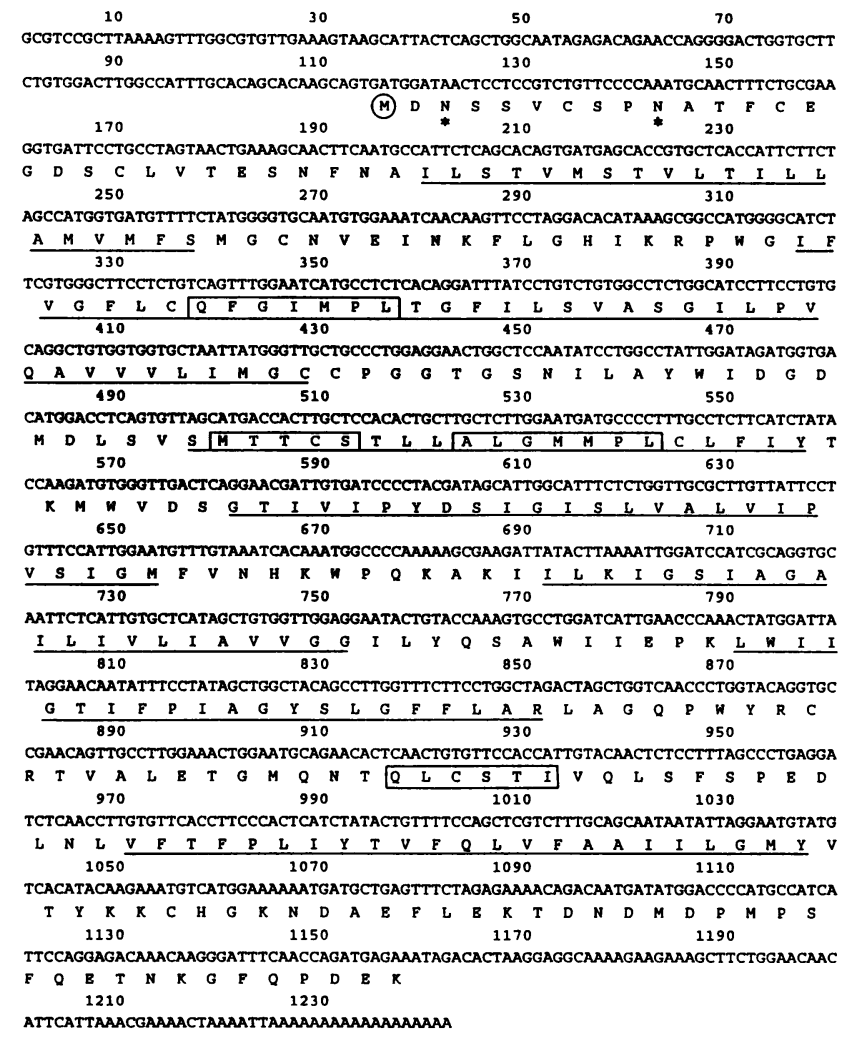

Figure 2. Sequence of the coding region of the rat ASBT. The complete sequence of clone $\mathrm{BS} 37 \mathrm{Cl}$ is shown. The initiator methionine is circled, potential $\mathrm{N}$-glycosylation sites are labeled with an asterisk, the conserved amino acid stretches are boxed, and the potential transmembrane domains are underlined.

stripped and reprobed with a full-length cDNA for cyclophilin, which appears to be constituitively expressed during this period of development $(22,23)$.

Protein analysis. Rabbit polyclonal antibodies were raised to the carboxy-terminal 14 aa of the hamster ASBT (Wong, M. H., manuscript submitted for publication) and were used for Western blot analysis, immunoprecipitation, and immunolocalization studies. The $\left[{ }^{35} \mathrm{~S}\right]-\mathrm{la}-$ beled in vitro translation product of $\mathrm{BS} 37 \mathrm{Cl}$ was immunoprecipitated in $150 \mathrm{mM} \mathrm{TrisCl}(\mathrm{pH} 7.4), 1 \% \mathrm{NP}-40$ with a 1:100 dilution of immune $\mathrm{IgG}$ and protein A Sepharose. The specificity of the precipitation was assessed by coincubation with $40 \mu \mathrm{g} / \mathrm{ml}$ of the 14-aa peptide. BBMV were prepared from developing terminal ileum by divalent cation precipitation as described previously (5). $25 \mu \mathrm{g}$ of BBMV was solubilized in Laemmli buffer at $37^{\circ} \mathrm{C}$ (identical results obtained at room temperature, $37^{\circ} \mathrm{C}$, and by boiling ), separated by $10 \%$ SDS-PAGE, and electrophoretically transferred to nitrocellulose (24). Blots were probed with a $1: 10,000$ dilution of immune IgG, and immunodetection was carried out using a chemiluminescent detection system (ECL; Amersham Corp., Arlington Heights, IL). The specificity of the immunodetection was assessed by preincubating a $2 \mathrm{mg} / \mathrm{ml}$ solution of the antibody with 1 $\mathrm{mg} / \mathrm{ml}$ of the 14-aa peptide. The role of nonspecific aggregation in the formation of the $92-\mathrm{kD}$ species was examined by the addition of $6 \mathrm{M}$ urea to the Laemmli solubilization buffer and by Western blotting of gelpurified 48 - and $92-\mathrm{kD}$ proteins. $400 \mu \mathrm{g}$ of ileal BBMV was separated by SDS-PAGE. The 48- and 92-kD bands were localized using prestained standards as markers (Bio-Rad Labs, Hercules, CA) and were excised from the gel. The proteins were electroeluted from the gel fragments with an Elutrap device according to the manufacturer's instructions (Schleicher \& Shuell, Inc., Keene, NH) and then were analyzed by Western blotting as described above. The role of $\mathrm{N}$-glycosylation was

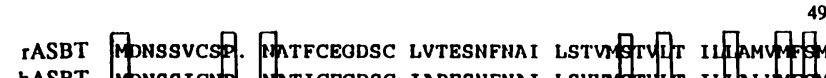

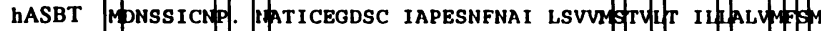

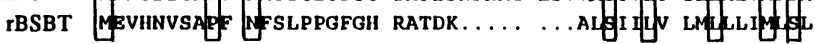

99

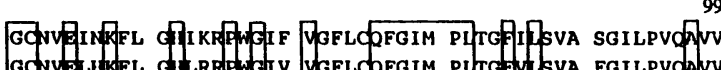

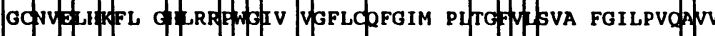

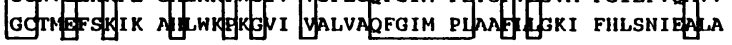

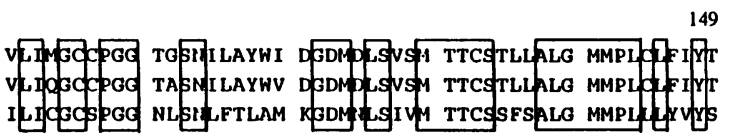

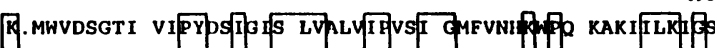

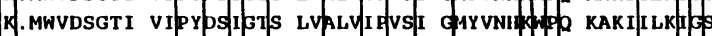

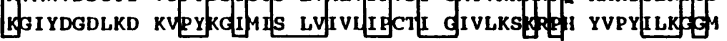

245

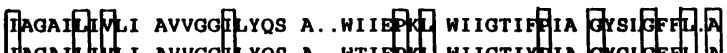

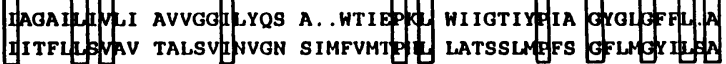

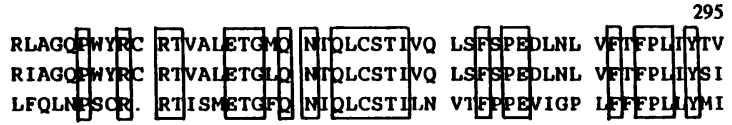

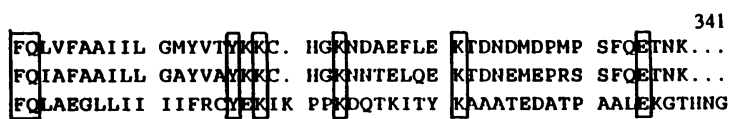

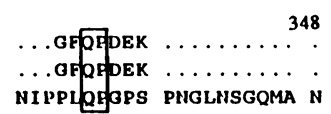

Figure 3. Comparison of the amino acid sequences of the rat ASBT and BSBT and the hamster ASBT. Amino acid identities in the three sequences are boxed. Numbering is based on the rat ASBT sequence.

assessed by digesting ileal BBMV from adult rats with $N$-glycanase. 25 $\mu \mathrm{g}$ of BBMV were solubilized in $0.4 \%$ SDS and $45 \mu \mathrm{g} \beta$-mercaptoethanol. Deglycosylation was carried out in $1.25 \% \mathrm{NP}-40$ with $0.3 \mathrm{U}$ of $N$ glycanase at $37^{\circ} \mathrm{C}$ overnight in the presence of $25 \mu \mathrm{g} / \mathrm{ml}$ leupeptin, 5 $\mu \mathrm{g} / \mathrm{ml}$ aprotinin, and $20 \mathrm{mg} / \mathrm{ml}$ phenylmethylsulfonyl fluoride. Control samples were incubated overnight in the same manner without the addition of $\mathrm{N}$-glycanase to ensure that the effects were not secondary to nonspecific degradation of the proteins. The products were then analyzed by Western blotting using 10\% SDS-PAGE. Immunolocalization was performed by indirect immunofluorescence using frozen-fixed tissue which was permeabilized with $0.2 \%$ Triton $\mathrm{X}-100$ and blocked with $0.05 \%$ saponin and $0.5 \mu \mathrm{g} / \mathrm{ml}$ nonspecific rat $\mathrm{IgG}$. Immunodetection was carried out with $0.1 \mathrm{mg} / \mathrm{ml}$ antipeptide antibody and $5 \mathrm{mg} / \mathrm{ml}$ FITC anti-rabbit $\mathrm{F}\left(\mathrm{ab}^{\prime}\right)_{2}$ fragment.

Transcriptional analysis. Nuclei were made from fresh ileum using a modification of the method described by Krasinski et al. (25). The distal small intestine was removed and flushed with $0.9 \%$ ice-cold $\mathrm{NaCl}$. The ileum was then dissected along its longitudinal axis, and mucosal scrapings were obtained. The mucosal scrapings were weighed, suspended in $10 \mathrm{vol}$ of homogenization buffer $(0.25 \mathrm{M}$ sucrose, $10 \mathrm{mM}$ Hepes, pH 8.0, $10 \mathrm{mM} \mathrm{MgCl}_{2}, 2 \mathrm{mM}$ DTT, 2.5\% NP-40), and incubated for $1 \mathrm{~h}$ on ice. The suspension was then homogenized using a PotterElvehjem homogenizer at $700 \mathrm{rpm}$ for 7 strokes, filtered through 2 layers of gauze, and centrifuged at $700 \mathrm{~g}$ for $5 \mathrm{~min}$. The pellet was resuspended in $2.5 \mathrm{ml}$ homogenization buffer and layered on top of a sucrose cushion (3.1 $\mathrm{M}$ sucrose, $1 \mathrm{mM} \mathrm{MgCl}, 1 \mathrm{mM}$ Hepes, $\mathrm{pH}$ 6.8). After centrifugation at $50,000 \mathrm{~g}$ for $80 \mathrm{~min}$ at $4^{\circ} \mathrm{C}$, the nuclear pellet was resuspended in storage buffer ( $20 \mathrm{mM}$ Tris, $\mathrm{pH} 8.0,40 \%$ glycerol, $5 \mathrm{mM} \mathrm{MgCl}_{2}$, $0.1 \mathrm{mM}$ EDTA, $2 \mathrm{mM}$ DTT) and counted using a methylene blue stain. 


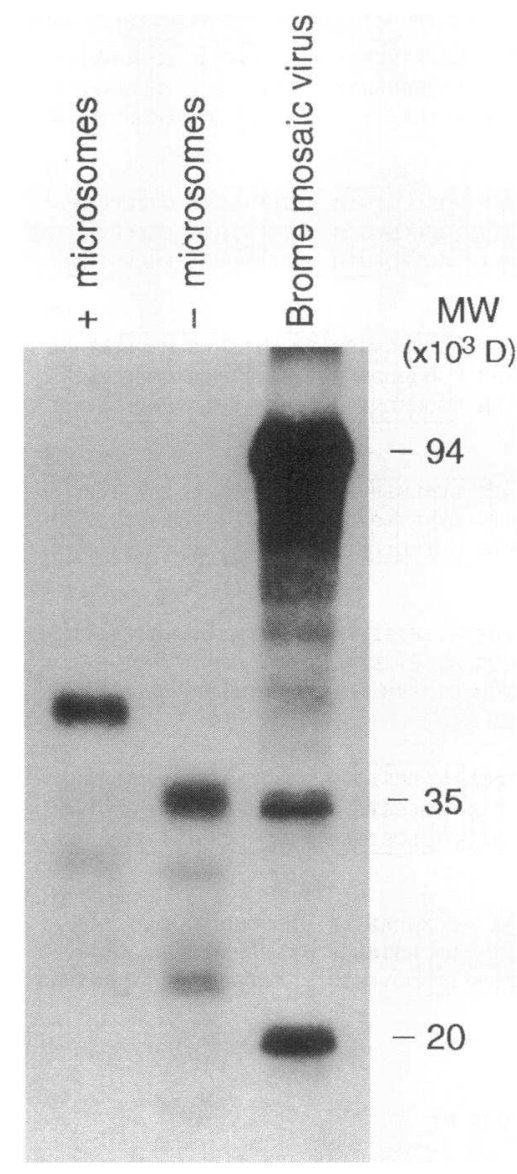

Figure 4. In vitro translation of BS37C1. $2 \mu \mathrm{g}$ of cRNA was translated using rabbit reticulocyte lysate \pm canine pancreatic microsomes in the presence of $\left[{ }^{35} \mathrm{~S}\right]$ methionine. Products were separated by $8 \%$ SDS-PAGE and analyzed by autofluorography. Known sizes of the Brome mosaic virus products were used for estimation of the size of the translation products.

Aliquots were stored at $-70^{\circ} \mathrm{C}$. For 7 -d-old animals, the procedure was identical apart from the following modifications. The distal small intestine was removed and used whole, as ileal mucosal scrapings are technically very difficult to obtain at this age. The homogenization buffer contained $0.1 \%$ Triton X-100 instead of $2.5 \% \mathrm{NP}-40$, as the higher concentration of detergent was not required to lyse the cells. This was confirmed by microscopic observation of the pellicle formed during the high sucrose spin and by relative yields of nuclei obtained with the two detergent concentrations. The difference in the method of preparation of the nuclei did not appear to affect transcription of the housekeeping genes $\gamma$-actin or cyclophilin (see Results).

Nuclear transcription reactions were carried out by the method of Diamond and Goodman with minor modifications (26). $2 \times 10^{7}$ nuclei were incubated for $30 \mathrm{~min}$ at $37^{\circ} \mathrm{C}$ in $20 \mathrm{mM}$ Tris-Cl ( $\mathrm{pH} \mathrm{8.0)}, 150$ $\mathrm{mM} \mathrm{KCl}, 5 \mathrm{mM} \mathrm{MgCl}_{2}, 3.5 \mathrm{mM}$ DTT, $20 \%$ glycerol, $50 \mathrm{mM}$ EDTA, $1 \mathrm{mM}$ of ATP, CTP, GTP, and $100 \mu \mathrm{Ci}$ of $\left[{ }^{32} \mathrm{P}\right] \mathrm{UTP}(3,000 \mathrm{Ci} / \mathrm{mmol}$; DuPont-New England Nuclear), in a final volume of $200 \mu \mathrm{l}$. Nuclei were treated sequentially with DNase $I$, proteinase $K$ and extracted with phenol/chloroform/isoamyl alcohol (25:24:1). The RNA was precipitated twice with sodium acetate and isopropanol. The pellet was washed twice with ethanol, resuspended in STE ( $100 \mathrm{mM} \mathrm{NaCl}, 10 \mathrm{mM} \mathrm{TrisCl}$, pH 8.0, 1 mM EDTA) buffer and passed through a Sephadex G-50 spin column (Boehringer Mannheim Corp., Indianapolis, IN). The nascent RNA transcripts were hybridized to cDNAs immobilized on nylon filters. cDNAs used were as follows: for ASBT, KpnI linearized BS37C1; positive controls, BamHI linearized rat $\gamma$-actin and PstI linearized rat cyclophilin; negative control, PstI linearized pBluescript II SK+ (Stratagene).

Filters were prehybridized at $45^{\circ} \mathrm{C}$ for $24 \mathrm{~h}$ with $50 \%$ deionized formamide, $5 \times$ Denhardt's, $4 \times$ SSC, $50 \mathrm{mM}$ Pipes, $2 \mathrm{mM}$ EDTA, pH 8.0, $0.1 \%$ SDS, and $200 \mu \mathrm{g} / \mathrm{ml}$ each of salmon sperm DNA and yeast tRNA. Hybridization was carried out for $48 \mathrm{~h}$ at $45^{\circ} \mathrm{C}$ using the

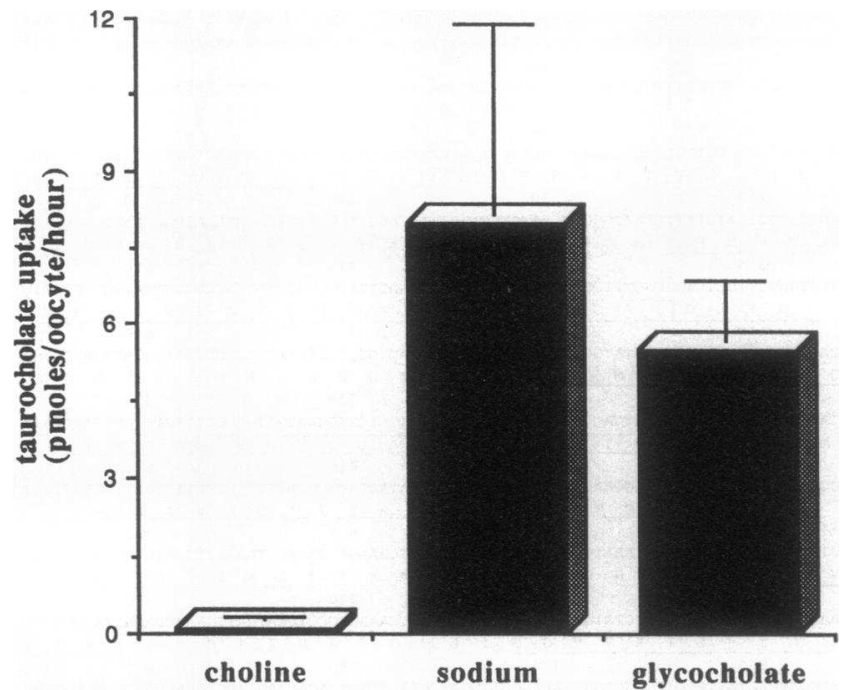

Figure 5. Oocyte expression of BS37C1. 9 ng of cRNA was injected into oocytes and $\left[{ }^{3} \mathrm{H}\right]$ taurocholate uptake was measured in the presence of $100 \mathrm{mM}$ choline chloride or $100 \mathrm{mM}$ sodium chloride $\pm 100 \mu \mathrm{M}$ glycocholate. Each bar represents the mean \pm standard deviation ( $n$ $=21$ ).

entire transcription product of $2 \times 10^{7}$ nuclei. The filters were then washed sequentially as follows: $2 \times$ SSC and $0.5 \%$ SDS for $20 \mathrm{~min}$ at $45^{\circ} \mathrm{C}$, the same buffer with RNase A (20 $\left.\mu \mathrm{g} / \mathrm{ml}\right)$ and RNase T1 $(700$ $\mathrm{U} / \mathrm{ml}$ ) for $30 \mathrm{~min}$ at $37^{\circ} \mathrm{C}, 2 \times \mathrm{SSC} / 0.5 \% \mathrm{SDS}$ at $65^{\circ} \mathrm{C}$ for $30 \mathrm{~min} \times 2$, $1 \times \mathrm{SSC} / 0.5 \% \mathrm{SDS}$ for $30 \mathrm{~min}$ at $65^{\circ} \mathrm{C}, 0.1 \times \mathrm{SSC} / 0.1 \% \mathrm{SDS}$ for 30 min at $65^{\circ} \mathrm{C}$. After rinsing in $2 \times \mathrm{SSC}$, the bands were quantitated using a PhosphorImager (Molecular Dynamics, Inc., Sunnyvale, CA), and the results were normalized to the total number of counts in the transcription reaction. The filters were exposed to Hyperfilm (Amersham Corp.) for $7-10 \mathrm{~d}$ at $-70^{\circ} \mathrm{C}$.

Statistical analysis. Means were compared using Students $t$ test.

\section{Results}

cDNA cloning and sequencing. A 206-bp product resulted from amplification using the rat ileal cDNA library as substrate and the degenerate oligonucleotides as primers. Sequence analysis of this product revealed that it had 88 and $62 \%$ nucleotide identity with the hamster ASBT and rat BSBT, respectively. Using this product to probe total RNA from multiple rat tissues at high stringency, a single predominant transcript was detected in rat ileum and kidney, but not jejunum or liver (data not shown). This 206-bp product was then used to screen 500,000 clones from the rat ileal cDNA library. Nine colonies were positive on tertiary screening and were subcloned into pBluescript. One of these clones, BS37C1, was sequenced on both strands using a series of oligonucleotide primers ${ }^{2}$ (Fig. 1). The other eight clones were analyzed by PCR using various combinations of the sequencing primers and/or primers derived from the lambda vector. In addition, two of the other clones were partially sequenced. By this analysis all nine clones were shown to encode ASBT cDNAs. Clone BS37C1 contained a 1,242bp insert, which encoded a 348-aa peptide with a calculated

2. Sequence data are available from GenBank under accession number U07183. 


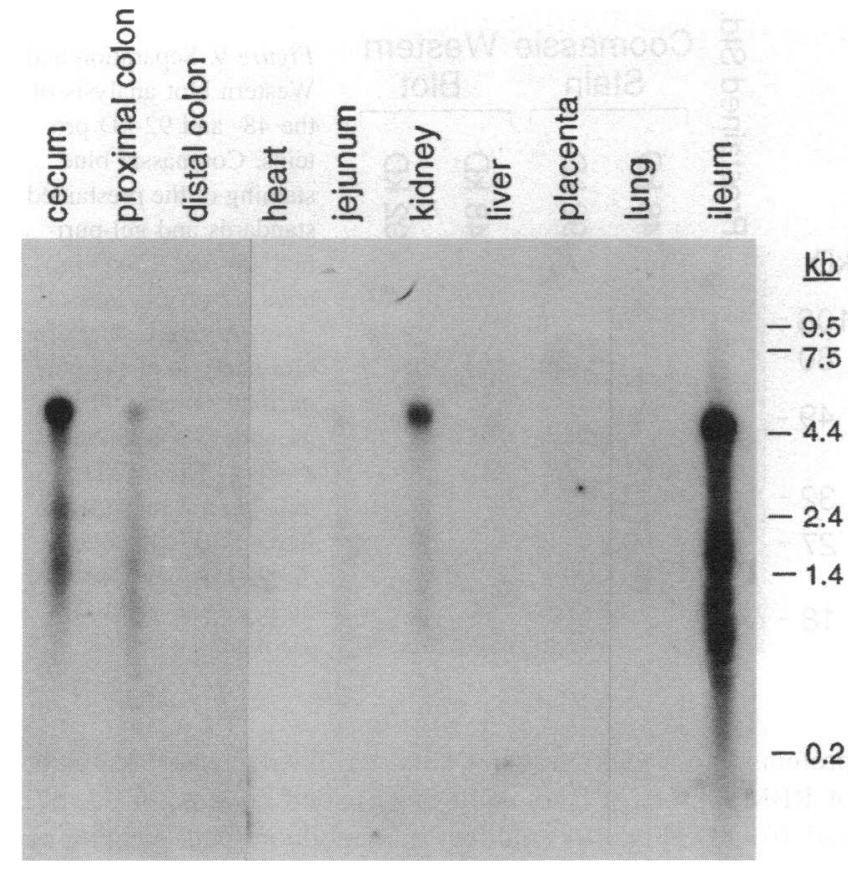

molecular mass of 38,079 D (Fig. 2). The initiator methionine (bp 116) was included in a Kozak consensus sequence (27) and was preceded by three in-frame stop codons (bp 26, 32, and 53). A poly (A) tract was found at position 1225, but was not preceded by an appropriate polyadenylation signal and thus is probably not the true $3^{\prime}$ end of this cDNA. Two potential $N$ glycosylation sites were identified at amino acids 3 and 10 . Kyte-Doolittle hydropathy plot analysis predicts a potential seven transmembrane topology similar to the predicted topologies for the rat BSBT and the hamster $\operatorname{ASBT}(13,14)$. Comparison of the amino acid sequences of the rat ASBT with the rat BSBT and the hamster ASBT sequences revealed 37 and $88 \%$ identity (64 and 95\% similarity), respectively (Fig. 3). There are four stretches of at least 5 aa which are conserved between the rat ASBT and BSBT and hamster ASBT sequences (aa 7581, 129-133, 137-143, 268-273). All but the last homologous sequence are found within potential membrane-spanning domains. Since the 14 carboxy-terminal amino acids of the hamster and rat ileal peptides are identical, a peptide antibody initially developed to study the hamster protein was equally useful in studying the rat transporter.

In vitro translation and oocyte expression. In vitro translation of the capped cRNA from clone BS37Cl resulted in a protein with a molecular mass of $\sim 38 \mathrm{kD}$ as compared with peptides generated from Brome mosaic virus RNA (Fig. 4). Glycosylation in the presence of canine pancreatic microsomes increased the apparent molecular mass to $\sim 48 \mathrm{kD}$. This glycosylated protein reverted back to the $38-\mathrm{kD}$ size when it was treated with $N$-glycanase (data not shown). The $38-\mathrm{kD}$ protein was immunoprecipitated by the antipeptide antibody, and this precipitation could be blocked by the 14 -aa peptide. $X$. laevis oocytes expressed sodium-dependent uptake of taurocholate 60 $\mathrm{h}$ after injection with $9 \mathrm{ng}$ of cRNA (sodium $8.0 \pm 3.7$ versus choline $0.2 \pm 0.1 \mathrm{pmol} /$ oocyte per $\mathrm{h}, n=21$, mean \pm standard deviation, $P<0.001$; Fig. 5). Uptake of $20 \mu \mathrm{M}$ taurocholate was inhibited $32 \%$ by $100 \mu \mathrm{M}$ glycocholate $(5.5 \pm 1.2 \mathrm{pmol} /$ oocyte per h, $n=11, P<0.001)$.

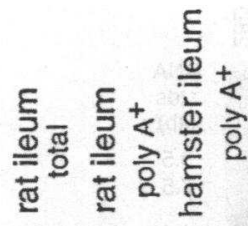

Figure 6. Northern blot analysis of the tissue distribution of the rat ASBT. Left blot: $4 \mu \mathrm{g}$ of poly (A) ${ }^{+}$RNA (except ileum $=0.2 \mu \mathrm{g}$ ) was probed with $\mathrm{BS} 37 \mathrm{C} 1$ and detected by autoradiography (exposure: $-70^{\circ} \mathrm{C}, 5 \mathrm{~d}$ ). Message is detected in cecum, proximal colon, kidney, and ileum, with significantly greater levels detected in ileum. Right blot: $4 \mu \mathrm{g}$ of rat total ileal RNA and $0.4 \mu \mathrm{g}$ each of rat and hamster poly $(\mathrm{A})^{+}$RNA (exposure: $-70^{\circ} \mathrm{C}, 16 \mathrm{~h}$ ). The signal intensity and size of the hamster mRNA are significantly less than that of the rat.

Messenger RNA analysis. Poly (A) ${ }^{+}$RNA from multiple tissues was probed with the 1,242-bp insert from clone BS37C1. 5.0-kb bands were detected in ileum, kidney, cecum, and proximal colon (Fig. 6). The message was most abundant in ileum (RNA loading $4 \mu \mathrm{g}$ for all tissues except ileum, $0.2 \mu \mathrm{g}$ ), with a decreasing gradient of expression from ileum to cecum to proximal colon. There was a very faint signal in liver and jejunum, and there was no signal in heart, placenta, and lung. A slight difference in mobility of the mRNA was seen when total and poly (A) ${ }^{+}$RNA were directly compared. This faster mobility of the ASBT message in the total RNA samples may be due to comigration with the $28 \mathrm{~S}$ ribosomal RNA. The transcript in rat appears to be $\sim 1 \mathrm{~kb}$ larger than the $4.0-\mathrm{kb}$ mRNA seen in the hamster. In addition, there appears to be a significantly greater abundance of the ASBT mRNA in the rat ileum as compared with the hamster ileum. Northern blot analysis of total RNA during ileal development revealed a strong signal in 21- and 28-d-old rats (Fig. 7). No message was detected using total RNA from 7-d-old animals, although a faint signal could be detected using poly (A) ${ }^{+}$RNA ( $\sim 1 \%$ of the signal intensity of 28-d-old animals, data not shown). There was a graded increase in signal intensity between 14 and $19 \mathrm{~d}$ with the most notable increase at $18 \mathrm{~d}$ after birth. Loading of the gels was checked by densitometry of the ethidium bromide staining of the 28S band, and RNA transfer was documented by the detection of equivalent signals using cyclophilin as a probe (23).

Protein analysis. Antipeptide immunoglobulin detected a ladder of proteins in adult rat ileal brush border membrane proteins. The smallest protein was $\sim 48 \mathrm{kD}$ with additional bands at 75,92 , and $130 \mathrm{kD}$ (Fig. 8). Preincubation with the 14-aa peptide blocked recognition of the 48-, 92-, and 130-kD bands, but not the $75-\mathrm{kD}$ protein. The $48-$ and $92-\mathrm{kD}$ bands were the most easily and reproducibly detected bands. Both the 48- and $92-\mathrm{kD}$ bands were detected using a variety of methods of sample preparation including various temperatures of solubilization, adding $6 \mathrm{M}$ urea to the solubilization buffer, and varying the amount and type of reducing agents. In addition, both 


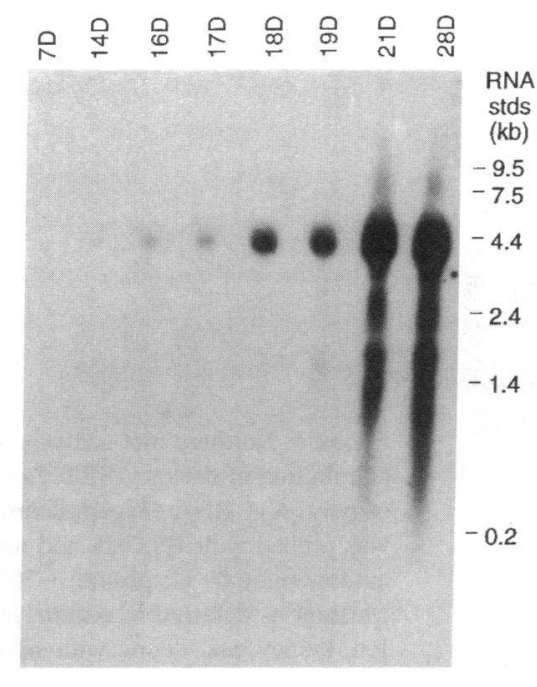

Cyclophilin

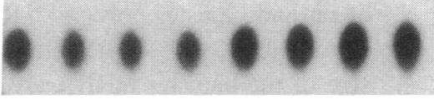

$28 S$

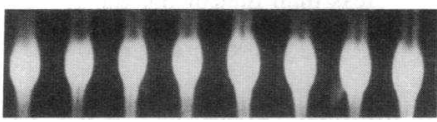

Figure 7. Northern blot analysis of the ontogeny of the rat ASBT. 20 $\mu \mathrm{g}$ of total RNA was probed with $\mathrm{BS} 37 \mathrm{Cl}$ and cyclophilin (exposure: $-70^{\circ} \mathrm{C}, 16 \mathrm{~h}$ ). Ethidium bromide staining of the $28 \mathrm{~S}$ band is shown in the bottom panel. Densitometric analysis of triplicate analyses of these ages revealed the following values relative to the signal at $28 \mathrm{~d}: 7 \mathrm{D}$ $=0.4 \%, 14 \mathrm{D}=0.4 \%, 16 \mathrm{D}=1.3 \%, 17 \mathrm{D}=2.1 \%, 18 \mathrm{D}=4.2 \%, 19 \mathrm{D}$ $=16 \%, 21 \mathrm{D}=66 \%, 28 \mathrm{D}=100 \%$.

the 48- and $92-\mathrm{kD}$ bands were detected in homogenates of ileal tissue (data not shown). Crude purification of the 48- and 92$\mathrm{kD}$ proteins by SDS-PAGE and reanalysis by Western blotting did not result in the formation of the $92-\mathrm{kD}$ band from the gelpurified $48-\mathrm{kD}$ proteins, nor was there breakdown of the $92-\mathrm{kD}$

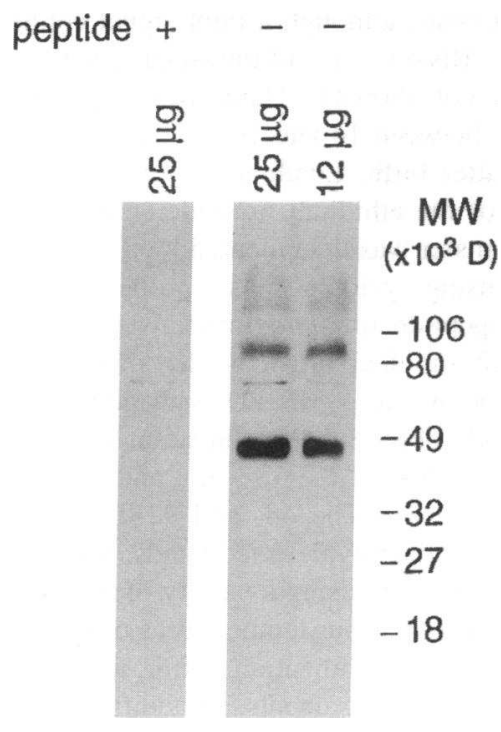

Figure 8. Western blot characterization of the ASBT using the antipeptide antibody. 48-, 75-, 92-, and $130-\mathrm{kD}$ proteins are detected in 12 and 25 $\mu \mathrm{g}$ of ileal brush border membrane proteins. Detection of the $75-\mathrm{kD}$ protein is not blocked by preincubation with the peptide.

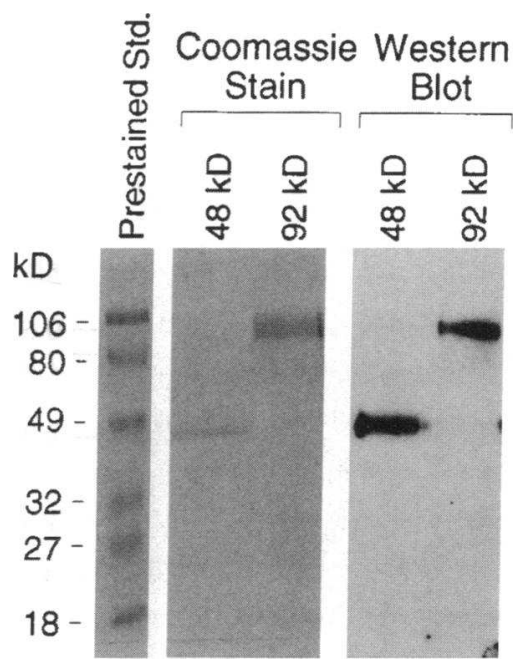

Figure 9. Separation and Western blot analysis of the 48 - and $92-\mathrm{kD}$ proteins. Coomassie blue staining of the prestained standards and gel-purified 48 - and $92-\mathrm{kD}$ proteins are seen in lanes 1 3 , respectively. Western blot analysis of the gelpurified 48- and 92-kD proteins is seen in lanes 4 and 5 . The $48-\mathrm{kD}$ proteins do not reaggregate into a $92-\mathrm{kD}$ band and the $92-\mathrm{kD}$ band does not disaggregate into a 48$\mathrm{kD}$ band.

proteins into a $48-\mathrm{kD}$ species (Fig. 9). $\mathrm{N}$-Glycanase treatment of BBMV proteins from adult rats yielded proteins of 35,67 , and $101 \mathrm{kD}$ (Fig. 10). Indirect immunofluorescent staining of terminal ileum from adult rats demonstrated decoration of the brush border membrane of villus but not crypt enterocytes (Fig. 11). There was no brush border staining observed in terminal ileum from 14-d-old rats (data not shown). Western analysis of the ontogeny of this protein revealed that the protein was first detectable at 19 postnatal $\mathrm{d}$, with a marked increase at 21 d (Fig. 12). A significant decrease in electrophoretic mobility of the ladder of proteins was noted between postnatal days 19 and 28 (Fig. 12).

Transcriptional analysis. Nuclear run-on assays were performed in duplicate using nuclei from pre- and post-weaning animals. A representative example of the results of one of the studies is seen in Fig. 13. The entire transcription reaction from $2 \times 10^{7}$ nuclei was hybridized to the plasmids identified in the

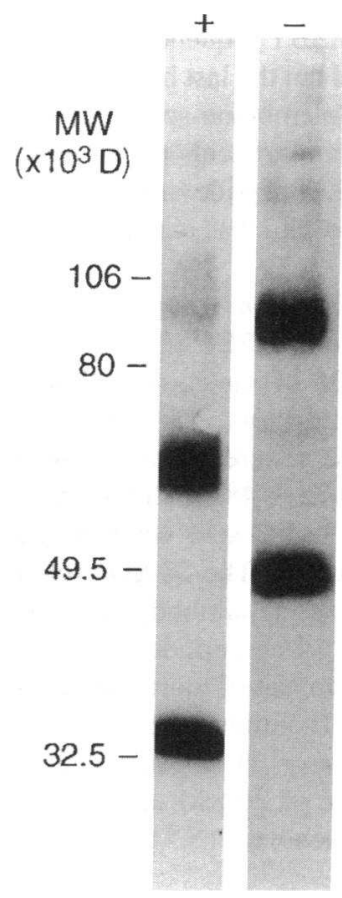

Figure 10. Deglycosylation of ASBT from ileal BBMV. $25 \mu \mathrm{g}$ of BBMV $\pm N$ glycanase treatment is analyzed by Western blot analysis. The 48-, 92-, and $130-\mathrm{kD}$ proteins deglycosylate to 35 , 67 , and $101 \mathrm{kD}$. 


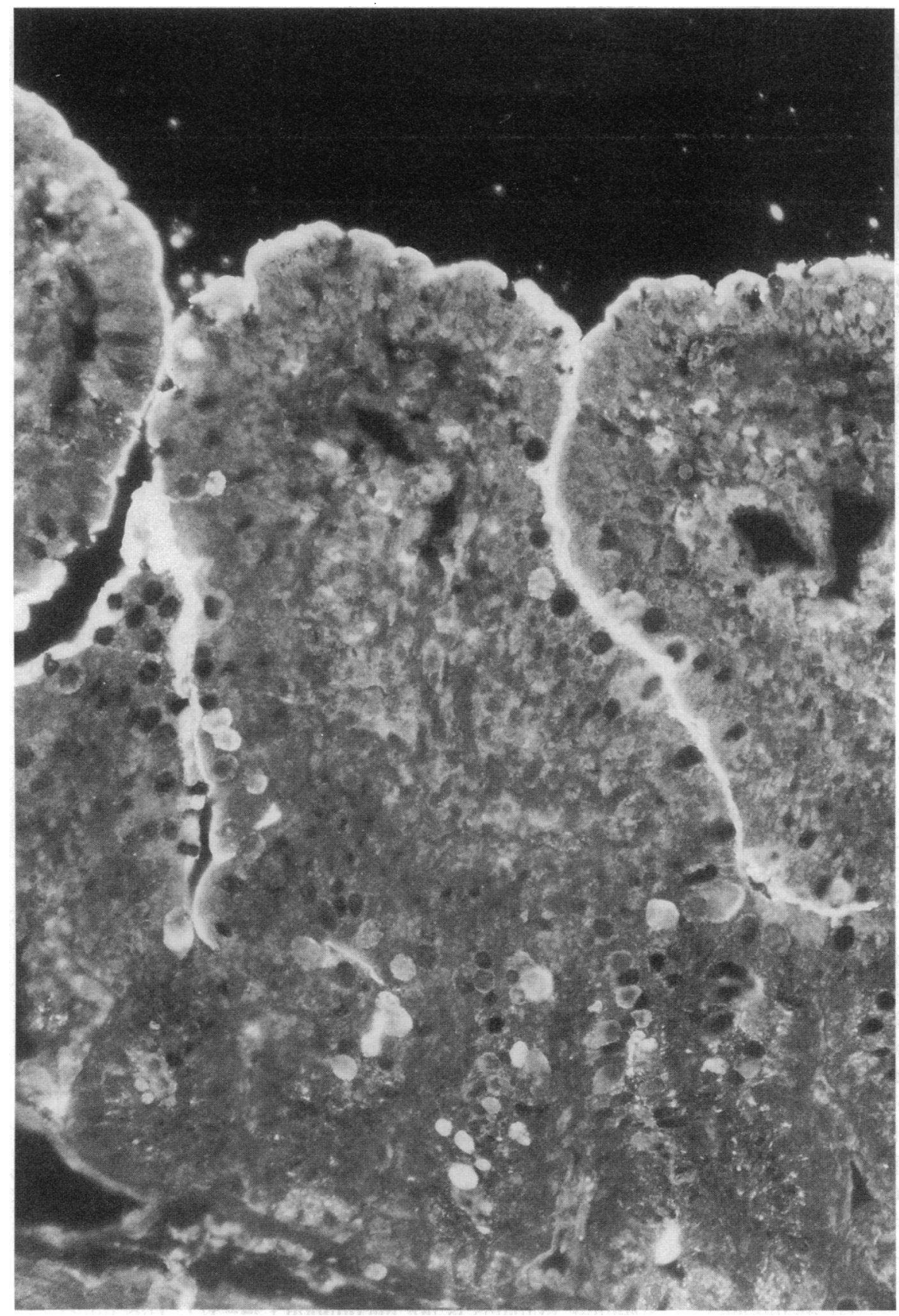

Figure 11. Indirect immunofluorescent detection of the rat ASBT. The villus brush border membrane is decorated with the ASBT antipeptide antibody. figure. The overall transcription reaction of the nuclei from 7d-old animals was approximately twice that of the 19- and 28-d-old animals. When corrected for the number of counts generated by the transcription reaction, the signal for $\gamma$-actin was similar for 7-, 19-, and 28-d-old animals. A faint signal of ASBT transcription could be seen in nuclei from 7-d-old rats, and there was a graded increase in this signal intensity at 19 and $28 \mathrm{~d}$ (ratio of the signals for the ASBT was $\sim 1: 6: 15$, for 7,19 , and $28 \mathrm{~d}$, respectively ).

\section{Discussion}

The development of the enterohepatic circulation of bile salts has been studied extensively in the rat including measurements of bile salt synthesis and pool size. Changes in the kinetics of hepatic and ileal bile acid transport during development have been analyzed using isolated perfused systems, intact cells, and highly purified membrane preparations $(1-9,11,12)$. Developmental changes in nutrition and hormonal milieu are also well characterized in the rat, and the effects of these factors on the ontogeny of bile acid transport have also been investigated. Rat-specific probes exist for molecular analysis of the hepatic basolateral transporter $(13,28,29)$ but have been unavailable for study of its homologue in the rat ileum. Degenerate oligonucleotide primers, based on amino acid homologies between the rat BSBT and the hamster ASBT, were used to amplify a ratspecific probe; this probe was used to screen a rat ileal cDNA library to obtain the rat ASBT. The functional importance of these areas of amino acid identity is suggested by the ability to use the sequences to design primers to amplify BSBT from 


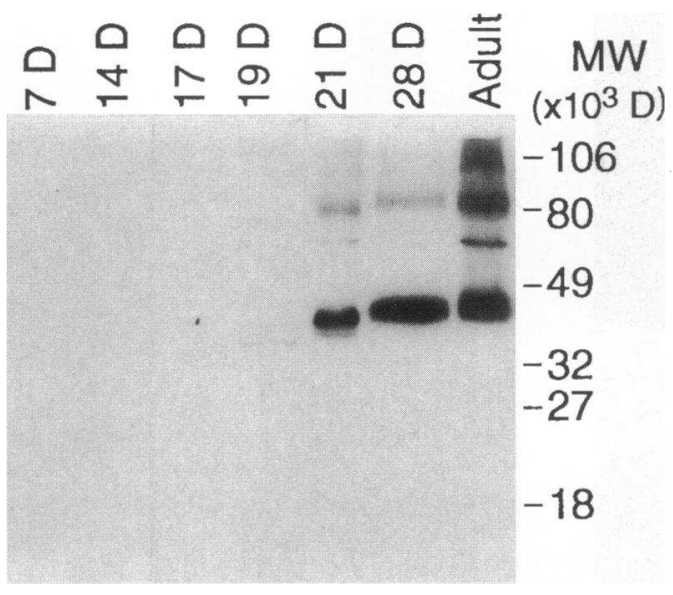

Figure 12. Western blot analysis of the ontogeny of the rat ASBT. 25 $\mu \mathrm{g}$ of ileal brush border membrane proteins was analyzed by Western blotting. A representative set of results is shown.

rabbit and human liver mRNA in addition to ASBT from rat ileal and kidney mRNA (Ananthanarayanan, M., B. Shneider, F. Suchy, unpublished data).

The cloning of the rat ASBT also permits direct nucleic acid and amino acid sequence comparison with the BSBT from the same species. Both proteins mediate sodium-dependent concentrative uptake of bile salts. Despite their similarity in function and general substrate specificity, significant differences exist between these carriers. The milieu in which these two carriers function is strikingly different, as the intestinal carrier is exposed to significantly higher concentrations of bile salts, which are intermixed in a complex array of bacterial and digestive substances. In addition, the BSBT is sorted to the basolateral membrane, while sorting of the ASBT is to the apical membrane. Subtle differences in substrate specificity have also been shown (30). These functional differences are probably reflected in the limited primary amino acid homology between these two transporters. It is thus not surprising that early attempts to identify the ileal bile acid transporter by hybridization with the rat BSBT gene were unsuccessful (30). Amino acid homologies that do exist between these two carriers may be involved in structural motifs, which are required for common functions, e.g., sodium dependence, bile acid binding, and translocation (Fig. 3). In particular, the role of the conserved membranespanning domains may be particularly relevant to bile acid translocation. Previous investigations have shown that sulfhydryl and $\epsilon$-amino modifying agents inhibit bile acid transport and thus the conserved cysteine and lysine residues at amino acids $51,105,132,185,195,270,317$, and 325 may also be particularly important for bile acid binding and sodium dependency $(31,32)$.

These studies clearly demonstrate that this cDNA encodes an ileal sodium-dependent bile acid cotransporter. cRNA expression in $X$. laevis oocytes imparts sodium-dependent bile acid transport capacity. Northern blot analysis shows that this mRNA is expressed in the terminal ileum, cecum, proximal colon, and kidney in adult rats. Functional studies have shown that there is sodium-dependent bile acid transport in both the ileum and proximal convoluted tubule of the kidney (33). Sodium-dependent bile acid transport has not been rigorously examined in the cecum and proximal colon and thus it is not

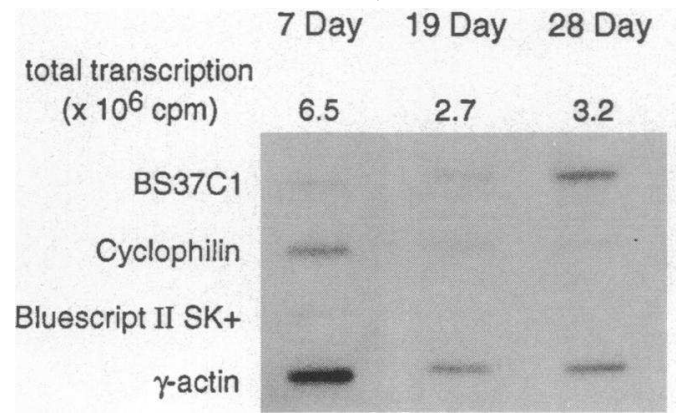

Figure 13. Nuclear run-on analysis. A representative nuclear run-on study is shown. The entire transcription reaction from $2 \times 10^{7}$ nuclei was hybridized to the plasmids identified in the figure. A graded increase in the signal intensity for the ASBT transcript is seen in nuclei from 7-, 19-, and 28-d-old animals. When corrected for the number of counts generated by the transcription reaction, the signal for $\gamma$-actin was similar for 7-, 19-, and 28-d-old animals while the ratio of the signals for the ASBT was $\sim 1: 6: 15$, respectively.

clear if the message detected in these studies is physiologically significant. It appears that the human ileal and kidney transporters are derived from the same gene (Wong, M. H., manuscript submitted for publication). The mRNA that is detected in the rat is significantly more abundant than the $4.0-\mathrm{kb}$ mRNA in the hamster and significantly larger than the 1.7-kb homologous mRNA in rat liver $(13,14)$. The size discrepancy between the 1.0-kb coding region and the 5.0-kb mRNA in the rat ileum indicates that there are significant untranslated regions in the rat ASBT transcript. The functional significance of these regions is currently unknown.

A variety of investigations suggest that the rat ASBT is a glycosylated villus enterocyte brush border membrane protein with a molecular mass of $\sim 48 \mathrm{kD}$. Primary amino acid sequence analysis, in vitro translation studies, and BBMV deglycosylation experiments indicate that the nonglycosylated form of this protein has a molecular mass of $35-38 \mathrm{kD}$. Based on both in vitro translation studies and Western blot analyses, the glycosylated in vivo product is at least $48 \mathrm{kD}$. The identities of the higher molecular mass species that are recognized by the antipeptide antibody are not clear at this time. It is possible that the $92-\mathrm{kD}$ protein is a homodimer of the $48-\mathrm{kD}$ protein. Aggregation of membrane proteins with multiple membranespanning domains is not uncommon (34-37). This dimerization theory is supported by the fact that both of these bands are deglycosylated by the same percentage to yield a $67-\mathrm{kD}$ band, which is nearly double the size of the $35-\mathrm{kD}$ band. In addition, both species undergo a similar developmental pattern. This proposed homodimer would need to be quite resistant to standard methods of disaggregation. The dimerization cannot be the result of simple aggregation as the gel-purified $48-\mathrm{kD}$ protein is stable as a $48-\mathrm{kD}$ species. In addition, higher molecular mass species were not observed using in vitro translation. An alternative explanation is that the $92-\mathrm{kD}$ band is another protein with a similar cross-reacting peptide sequence. The relationship of this $92-\mathrm{kD}$ band and the $99-\mathrm{kD}$ proteins that have been suggested as candidate ileal bile acid transporters will require further investigations $(38,39)$. Preliminary analyses of renal brush border membrane proteins also reveal 48 - and $92-\mathrm{kD}$ proteins (Shneider, B. L., manuscript in preparation). Two potential $N$ glycosylation sites are predicted and correspond to the two of 
seven potential sites that are utilized in the rat BSBT (28). Indirect immunofluorescent microscopy localized this protein to the brush border membrane of villus but not crypt enterocytes, which is consistent with transport studies (40).

Molecular characterization of the development of this transporter indicates that mRNA and protein expression increases at the time of weaning, consistent with functional data regarding the development of sodium-dependent ileal bile acid transport (1-5). In particular, the onset of transport activity seems to correlate with an abrupt increase in mRNA expression. It appears that the steady state levels of mRNA are regulated, in part, at the level of transcription. The order of magnitude of the difference between changes in mRNA abundance $(\sim 100$-fold $)$ and transcription rates $(\sim 15$-fold $)$ suggests a potential role of message stability in this regulation. Transcriptional regulation of intestinal enzymes at the time of weaning has been shown with the brush border hydrolase, sucrase-isomaltase (25), where there also are abrupt changes in mRNA levels at the time of weaning. The marked increase in steady state mRNA levels is accompanied by the detection of this protein in brush border membrane vesicles, and it is at this developmental stage that $\mathrm{Na}^{+}$-dependent concentrative uptake is seen in brush border membrane vesicles (5). The increase in molecular mass between $21 \mathrm{~d}$ and adult appears to be the result of alterations in posttranslational modification. A similar phenomenon has been observed during the ontogeny of the rat BSBT (Hardikar, W. and F. Suchy, unpublished observation). In both the liver and intestine, this change in electrophoretic mobility is coincident with a maturation of transport function to adult levels. Thus, posttranslational modifications may be important for the development of full transport function. Developmental changes in glycoprotein composition have been described for lactase-phlorizin hydrolase (41).

In summary, a rat ileal sodium-dependent bile acid cotransporter has been cloned and expressed in oocytes. It is a $48-\mathrm{kD}$ glycoprotein which is expressed at the brush border membrane of ileal villus enterocytes. Its primary amino acid sequence is highly homologous with the previously cloned hamster transporter and is divergent from the liver homologue. Similar topologies and areas of amino acid identity suggest regions required for sodium-dependent bile acid transport. The developmental regulation of the rat ileal transporter is partially controlled at the level of transcription, resulting in abrupt increases in ASBT steady state mRNA and protein levels at the time of weaning. During this time the apparent molecular mass of the transporter also changes. The isolation and characterization of the rat ASBT will facilitate analysis of the molecular mechanisms underlying the complex regulation of the ileal bile acid transporter.

\section{Acknowledgments}

The authors would like to thank Dr. M. Susan Moyer for her assistance with the oocyte expression studies and Dr. M. Ananthanarayanan and Dr. S. Karpen for their helpful advice.

This work was supported in part by grants from the National Institutes of Health (DK 02076, DK 34989, DK 43509, HD 20632, and HD 27757 to B. L. Shneider, D.-M. Christie, W. Hardikar, and F. J. Suchy and DK 08718 to P. A. Dawson and M. H. Wong) and an Industry Research Scholar Award (to P. A. Dawson and M. H. Wong) from the American Gastroenterological Association Foundation.

\section{References}

1. Lester, R., R. A. Smallwood, J. M. Little, A. S. Brown, G. J. Piasecki, and B. T. Jackson. 1977. Fetal bile salt metabolism. The intestinal absorption of bile salt. J. Clin. Invest. 59:1009-1016.
2. Little, J. M., and R. Lester. 1980. Ontogenesis of intestinal bile salt absorption in the neonatal rat. Am. J. Physiol. 239:G319-G323.

3. de Belle, R. C., V. Vaupshas, B. B. Vitullo, L. R. Haber, E. Shaffer, G. G. Mackie, H. Owen, J. M. Little, and R. Lester. 1979. Intestinal absorption of bile salts: immature development in the neonate. J. Pediatr. 94:472-476.

4. Barnard, J. A., F. K. Ghishan, and F. A. Wilson. 1985. Ontogenesis of taurocholate transport by rat ileal brush border membrane vesicles. J. Clin. Invest. 75:869-873.

5. Moyer, M. S., J. E. Heubi, A. L. Goodrich, W. F. Balistreri, and F. J. Suchy. 1986. Ontogeny of bile acid transport in brush border membrane vesicles from rat ileum. Gastroenterology. 90:1188-1196.

6. Barnard, J. A., and F. K. Ghishan. 1986. Methylprednisolone accelerates the ontogeny of sodium-taurocholate cotransport in rat ileal brush border membranes. J. Lab. Clin. Med. 108:549-555.

7. Heubi, J. E. 1986. Role of thyroxine on postnatal development of ileal bile salt transport. Am. J. Physiol. 251:G237-G242.

8. Suchy, F. J. 1989. Development of bile formation and hepatic excretory function. In Human Gastrointestinal Development. E. Lebenthal, editor. Raven Press, New York. 623-647.

9. Shneider, B. L., G. A. Michaud, A. B. West, and F. J. Suchy. 1993. The effects of bile acid feeding on the development of ileal bile acid transport. Pediatr Res. 33:221-224.

10. Yeh, K. Y., and P. R. Holt. 1986. Ontogenic timing mechanism initiates the expression of rat intestinal sucrase activity. Gastroenterology. 90:520-526.

11. Schwarz, S. M., J. B. Watkins, and S. C. Ling. 1990. Taurocholate transport by brush-border membrane vesicles from the developing rabbit ileum: structure/ function relationships. J. Pediatr. Gastroenterol. Nutr. 10:482-489.

12. Heubi, J. E., and J. L. Fellows. 1990. Absence of relationship between the postnatal development of ileal active taurocholate transport and microvillus membrane fluidity. J. Develop. Physiol (Oxf.). 13:135-139.

13. Hagenbuch, B., B. Stieger, M. Foguet, H. Lubbert, and P. J. Meier. 1991. Functional expression cloning and characterization of the hepatocyte $\mathrm{Na}^{+} /$bile acid cotransport system. Proc. Natl. Acad. Sci. USA. 88:10629-10633.

14. Wong, M. H., P. Oelkers, A. L. Craddock, and P. A. Dawson. 1994. Expression cloning and characterization of the hamster ileal sodium-dependent bile acid transporter. J. Biol. Chem. 269:1340-1347.

15. Kaslow, D. C. 1986. A rapid biochemical method for purifying lambda DNA from phage lysates. Nucleic Acids Res. 14:6767.

16. Connell, C., S. Fung, C. Heiner, J. Bridgham, V. Chakerian, E. Heron, B. Jones, S. Menchen, W. Mordan, M. Raff, et al. 1987. Automated DNA sequence analysis. Biotechniques. 5:342-348.

17. Benton, W. D., and R. W. Davis. 1977. Screening $\lambda$ gt recombinant clones by hybridization to single plaques in situ. Science (Wash. DC). 196:180-182.

18. Ahlquist, P., V. Luckow, and P. Kaesberg. 1981. Complete nucleotide sequence of brome mosaic virus RNA 3. J. Mol. Biol. 153:23-38.

19. Ahlquist, P., R. Dasgupta, and P. Kaesberg. 1984. Nucleotide sequence of the brome mosaic virus genome and its implications for viral replication. $J$. Mol. Biol. 172:369-383.

20. Shneider, B. L., and M. S. Moyer. 1993. Characterization of endogenous carrier-mediated taurocholate efflux from Xenopus laevis oocytes. J. Biol. Chem. 268:6985-6988.

21. Chirgwin, J. M., A. E. Przybyla, R. J. MacDonald, and W. J. Rutter. 1979. Isolation of biologically active ribonucleic acid from sources enriched in ribonuclease. Biochemistry. 18:5294-5299.

22. Danielson, P. E., S. Forss-Petter, M. Brow, L. Calavetta, J. Douglass, R. J. Milner, and J. Gregor Sutcliffe. 1988. p1B15: A cDNA clone of the rat mRNA encoding cyclophilin. DNA (NY). 7:261-267.

23. Hylemon, P. B., E. C. Gurley, R. T. Stravitz, J. S. Litz, W. M. Pandak, J. Y. L. Chiang, and Z. R. Vlahcevic. 1992. Hormonal regulation of cholesterol $7 \alpha-$ hydroxylase mRNA levels and transcriptional activity in primary rat hepatocyte cultures. J. Biol. Chem. 267:16866-16871.

24. Laemmli, U. K. 1970. Cleavage of structural proteins during the assembly of the head of bacteriophage $\mathrm{T}_{4}$. Nature (Lond.). 227:680-685.

25. Krasinski, S. D., G. Estrada, K.-Y. Yeh, M. Yeh, P. G. Traber, E. H. M. M. Rings, H. A. Buller, M. Verhave, R. K. Montgomery, and R. J. Grand. 1994. Transcriptional regulation of intestinal hydrolase biosynthesis during postnatal development in rats. Am. J. Physiol. 267:G584-G594.

26. Diamond, D. J., and H. M. Goodman. 1985. Regulation of growth hormone messenger RNA synthesis by dexamethasone and triiodothyronine: transcriptional rate and mRNA stability changes in pituitary tumor cells. J. Mol. Biol: 181:4162.

27. Kozak, M. 1989. The scanning model for translation: an update. J. Cell Biol. 108:229-241.

28. Stieger, B., B. Hagenbuch, L. Cornacchia, A. Schroeder, L. Landmann, and P. J. Meier. 1993. Molecular properties of the $\mathrm{Na}^{+}$-dependent taurocholate cotransporting polypeptide (Ntcp) of rat liver. Hepatology. 18:143a. (Abstr.)

29. Ananthanarayanan, M., O. C. Ng, J. L. Boyer, and F. J. Suchy. 1994. Characterization of the cloned rat liver sodium-bile acid cotransporter using cterminal and fusion protein antibodies. Am. J. Physiol. 267:G637-G643.

30. Shneider, B., M. Ananthanarayanan, C. Schteingart, G. Michaud, B. Ha- 
genbuch, P. Meier, A. Hofmann, and F. Suchy. 1992. Physiologic, immunologic and molecular differences in hepatic and ileal sodium-dependent bile acid transport. Gastroenterology. 102:888a. (Abstr.)

31. Blumrich, M., and E. Petzinger. 1993. Two distinct types of SH-groups are necessary for bumetanide and bile acid uptake into isolated rat hepatocytes. Biochim. Biophys. Acta. 1149:278-284.

32. Kramer, W., S. Nicol, F. Girbig, U. Gutjahr, S. Kowalewski, and H Fasold. 1992. Characterization and chemical modification of the $\mathrm{Na}^{+}$-dependent bile-acid transport system in brush-border membrane vesicles from rabbit ileum. Biochim. Biophys. Acta. 1111:93-102.

33. Wilson, F. A., G. Burckhardt, H. Murer, G. Rumrich, K. Ullrich. 1981 Sodium-coupled taurocholate transport in the proximal convolution of the rat kidney in vivo and in vitro. J. Clin. Invest. 67:1141-1150.

34. Danbolt, N. C., G. Pines, and B. I. Kanner. 1990. Purification and reconsti tution of the sodium- and potassium-coupled glutamate transport glycoprotein from rat brain. Biochemistry. 29:6734-6740.

35. Fliesler, S. J., and S. F. Basinger. 1985. Tunicamycin blocks the incorporation of opsin into retinal rod outer segment membranes. Proc. Natl. Acad. Sci. USA. 82:1116-1120.
36. Smith, C. D., B. A. Hirayama, and E. M. Wright. 1992. Baculovirusmediated expression of the $\mathrm{Na}^{+} /$glucose cotransporter in $\mathrm{Sf} 9$ cells. Biochim. Biophys. Acta. 1104:151-159.

37. Sahin-Toth, M., M. C. Lawrence, and H. R. Kaback. 1994. Properties of permease dimer, a fusion protein containing two lactose permease molecules from Escherichia coli. Proc. Natl. Acad. Sci. USA. 91:5421-5425.

38. Kramer, W., G. Burckardt, F. A. Wilson, and G. Kurz. 1983. Bile saltbinding properties in brush border membrane vesicles from rat small intestine revealed by photoaffinity labeling. J. Biol. Chem. 258:3623-3627.

39. Gong, Y.-Z., P. P. Zwarych, M. C. Lin, and F. A. Wilson. 1991. Effect of antiserum to a $99 \mathrm{kDa}$ polypeptide on the uptake of taurocholate acid by rat ileal brush border membrane vesicles. Biochem. Biophys. Res. Commun. 179:204209.

40. Kapadia, C. R., and L. K. Essandoh. 1988. Active absorption of vitamin $B_{12}$ and conjugated bile salts by guinea pig ileum occurs in villous and not crypt cells. Dig. Dis. Sci. 33:1377-1382.

41. Buller, H. A., E. Rings, D. Pajkrt, R. K. Montgomery, and R. J. Grand. 1990. Glycosylation of lactase-phlorizin hydrolase in rat small intestine during development. Gastroenterology. 98:667-675. 